Article

\title{
Hydrodenitrogenation of porphyrin on Ni-Mo based catalysts
}

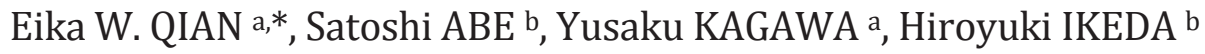 \\ a Department of Chemical Engineering, Tokyo University of Agriculture and Technology, 2-24-16 Nakacho, Koganei, Tokyo 184-8588, Japan \\ b Nippon Ketjen Co. Ltd, 17-4, Isoura-cho, Niihama-shi, Ehime792-0002, Japan
}

\section{A R T I C L E I N F O}

Article history:

Received 4 January 2013

Accepted 9 January 2013

Published 20 January 2013

\section{Keywords:}

Hydrodenitrogenation

Porphyrin

Nickel molybdenum catalyst

Phosphorus

\begin{abstract}
A B S T R A C T
The hydrodenitrogenation (HDN) of porphyrins was carried out over a series of phosphorus containing $\mathrm{NiMo} / \mathrm{Al}_{2} \mathrm{O}_{3}$ catalysts using a fixed-bed flow reaction system. A method of quantitative analysis of the porphyrin and its derivatives produced by HDN was established. In HDN of porphyrin, four types of hydrocarbons: $\mathrm{C}_{8}$ alkanes, $\mathrm{C}_{8}$ alkenes, $\mathrm{C}_{9}$ alkanes, and $\mathrm{C}_{10}$ alkanes, and two groups of nitrogen-containing compounds: alkyl substituted bipyrrolidines (alkylbipyrrolidines) and alkyl substituted tripyrrolidines (alkyltripyrrolidines) were identified. The hydrogenolysis of porphyrins occurred rapidly at lower temperature but higher temperatures were required for the HDN of porphyrins. The NiMoP3 catalyst showed the highest catalytic activity for the HDN of porphyrins. Based on the characterization of the supports and catalysts, it is suggested that the dispersion of Mo is improved and the number of weak acidic sites on the NiMoP catalysts increases with the addition of phosphorus.
\end{abstract}

(C) 2013, Dalian Institute of Chemical Physics, Chinese Academy of Sciences. Published by Elsevier B.V. All rights reserved.

\section{Introduction}

In an oil refinery, crude oil is distilled into several fractions, in which naphtha and gas oil have both high value and high demand, but the heavier oil, i.e., vacuum gas oil (VGO) and residue have low value and need. The demand for clean oils such as gasoline, kerosene, and light gas oil continues to increase with the economic development of developing countries such as China and India in recent years. In contrast, the supply of crude oil is becoming more and more heavy. Therefore, processes that convert heavy oil to lighter fuel oil such as the conventional fluid catalytic cracking (FCC) and/or residue FCC (RFCC) process become more and more important.

Fluidized catalytic cracking plays an important role in a refinery to transform the heavy oil fractions into gasoline and light gas oil [1]. In FCC and/or RFCC process, the catalyst is poisoned by the nitrogen-containing compounds present in
VGO or residue. Therefore, hydrodenitrogenation (HDN) of VGO and residue is a very important process to prevent the deactivation of the catalyst. However, there are a lot of large molecular weight compounds that contain nitrogen, such as porphyrins, present in VGO and atmospheric residue. Furthermore, the behaviors of these compounds in HDN have barely been investigated because it is difficult to analyze either the compounds or their derivatives produced in HDN. The elucidation of the behaviors of these compounds in HDN is indispensable to develop new hydrotreating catalysts for VGO and atmospheric residue [1]. Although it is well known that a catalyst with a higher hydrogenation activity is preferable for HDN, less quantitative information is available for the catalytic chemistry of HDN than for hydrodesulfurization (HDS). Moreover, the conventional hydrotreating catalysts such as CoMo or Ni$\mathrm{Mo} / \mathrm{Al}_{2} \mathrm{O}_{3}$ are more difficult and less effective for the HDN of heavy gas oil because of the high nitrogen content and their

\footnotetext{
* Corresponding author. Tel: +81-42-388-7410; E-mail: whqian@cc.tuat.ac.jp This work was supported by a research project of The Japan Petroleum Institute commissioned by the Japan Petroleum Cooperation Center, subsidized by the Ministry of Economy, Trade, and Industry.
}

DOI: $10.1016 /$ S1872-2067(11)60514-7 
polycyclic ring structures [2-5]. Thus, in the present study, 2,3,7,8,12,13,17,18-octaethyl-21H,23H-porphyrin (abbreviated as porphyrin) was used as a large molecular weight nitrogen-containing compound present in VGO and residue, and HDN was carried out on it using a pressurized fixed-bed flow reaction system. Before starting, an analytic method for the porphyrin and its derivatives from HDN was established.

There are several approaches to develop new HDN catalysts such as the use of a novel active metal [6-8], novel supports $[3,9,10]$, improvement in the preparation method, or the activation method [11], and the improvement of the support using fluorine, phosphorus, or boron [3-5]. It has also been proposed that the addition of phosphorus to the alumina support could improve the hydrogenation performance of Mo-based catalysts $[4,5]$. Generally, Ni-promoted catalysts, which show higher hydrogenation activity, are more suitable for HDN than Co-promoted catalysts $[1,12]$. Thus, a series of $\mathrm{NiMo} / \mathrm{Al}_{2} \mathrm{O}_{3}$ catalysts with added phosphorus were prepared in the present study and used for the HDN of the porphyrin. The effects of the reaction conditions such as temperature and WHSV, and the addition of phosphorus on HDN of porphyrin were investigated.

\section{Experimental}

\subsection{Catalysts preparation and characterization}

Phosphorus-containing alumina supports $\left(\mathrm{P} / \mathrm{Al}_{2} \mathrm{O}_{3}\right)$ were prepared using the incipient wetness impregnation method. In the preparation, an aqueous solution of $\left(\mathrm{NH}_{4}\right)_{2} \mathrm{HPO}_{4}$ with the desired concentration of phosphorus was used. After impregnation, the supports were dried at $120^{\circ} \mathrm{C}$ for $1 \mathrm{~h}$ and then calcined in air at $450{ }^{\circ} \mathrm{C}$ for $12 \mathrm{~h}$. Then, the phosphorus-containing alumina supports were used to prepare a series of NiMoP catalysts using an incipient wetness co-impregnation, in which $\mathrm{Ni}\left(\mathrm{NO}_{3}\right)_{2} \cdot 6 \mathrm{H}_{2} \mathrm{O}$ and $\left(\mathrm{NH}_{4}\right)_{6} \mathrm{Mo}_{7} \mathrm{O}_{24} \cdot 4 \mathrm{H}_{2} \mathrm{O}$ were used $[13,14]$. After impregnation, the catalyst was dried at $120^{\circ} \mathrm{C}$ for $1 \mathrm{~h}$, and then calcined in air at $450^{\circ} \mathrm{C}$ for $12 \mathrm{~h}$. All catalysts contained ca. $16 \mathrm{wt} \% \mathrm{MoO}_{3}$ and $\mathrm{Ni} / \mathrm{Mo}$ molar ratio of ca. 0.4 but contained different molar ratios of $\mathrm{P} / \mathrm{Mo}(0-1.0)$. The catalysts with $\mathrm{P} / \mathrm{Mo}$ molar ratio of $0,0.1,0.3$, and 1.0 were denoted as NiMo, NiMoP1, NiMoP3, and NiMoP10, respectively.

The catalysts prepared were characterized using X-ray fluorescence spectroscopy (XRF, Shimadzu, Rayny EDX800), N2 adsorption-desorption (Beckmann, SA-3100), Fourier transform infrared spectroscopy (FT-IR, Shimadzu, IR Prestige-21), probe molecule ( $\mathrm{NO}$ and $\mathrm{NH}_{3}$ ) adsorption, and $\mathrm{NH}_{3}$ temperature-programmed desorption ( $\left.\mathrm{NH}_{3}-\mathrm{TPD}\right)$.

\subsection{Catalytic activity test}

HDN activity tests were carried out in a pressurized fixed-bed reaction system; details of this reactor were described elsewhere $[13,14]$. After calcined overnight in the air at $400{ }^{\circ} \mathrm{C}$, the test catalyst was presulfided at $400{ }^{\circ} \mathrm{C}$ for $3 \mathrm{~h}$ using a $5 \% \mathrm{H}_{2} \mathrm{~S}-95 \% \mathrm{H}_{2}$ at a flow rate of $1.8 \mathrm{~L} / \mathrm{h}$. The reactor was then cooled in the hydrogen stream to the reaction temperature and pressurized with hydrogen. A tetralin solution with 0.10 wt $\%$ of the porphyrin was then introduced into the reactor by a high-pressure liquid pump (Kyowa Seimitsu KHD-16).

The reactions were carried out under the following conditions: pressure $5.0 \mathrm{MPa}$, temperature $300-360^{\circ} \mathrm{C}$, catalyst 0.4 g, WHSV $=39-100 \mathrm{~h}^{-1}$. Polysulfide, which is readily transformed to $\mathrm{H}_{2} \mathrm{~S}$ in HDN and stabilizes the reactions, was added to the feed solution.

After stabilizing the reaction for $4 \mathrm{~h}$, the liquid product was sampled from a gas-liquid separator every $15 \mathrm{~min}$. Porphyrin in solution before and after HDN were analyzed using GPC (Tosoh, HPLC-8020; Column: G-2000HXL-G-2000HXL-G300HXL; Oven: $40{ }^{\circ} \mathrm{C}$; Carrier liquid: THF; RI detector). Then, various porphyrin derivatives in HDN in the liquid product, sampled from the gas-liquid separator, were analyzed by GC-FID (Shimadzu GC 17A) for the hydrocarbon products, and GC-FTD (Shimadzu GC 2010) for the nitrogen-containing compounds. The total nitrogen content of the liquid samples was determined using a total nitrogen content analyzer ND-100 (Dia Instruments). Various HDN products were identified using GC-MS (Shimadzu QP 5050A) and GC-FTD.

\section{Results and discussion}

\subsection{Characterization results}

The BET specific surface area and porous volumes of the prepared catalysts and their compositions as determined by XRF are listed in Table 1. The alumina support had the largest specific surface area and porous volume. There was no significant change in the pore distribution although the specific surface area and porous volume decreased slightly with increasing phosphorus content. This means that the microporous structure of alumina remains after adding phosphorus. Similarly for the NiMoP catalysts, the BET specific surface area and porous volume decreased with increasing phosphorus content and active metals loading. However, this depended on the supports, as it was found that the peak of the $6 \mathrm{~nm}$ diameter micropore disappeared for NiMoP10, indicating that some micropores were blocked with excess phosphorus.

Figure 1 shows the FT-IR spectra of several $\mathrm{P} / \mathrm{Al}_{2} \mathrm{O}_{3}$ supports with different phosphorus contents. In the alumina support, four bands (3688, 3735, 3780, and $3798 \mathrm{~cm}^{-1}$ ) were observed. These are attributed to the $\mathrm{OH}$ stretching vibration of

Table 1

Compositions, BET specific surface area, and porous volume of the supports and catalysts.

\begin{tabular}{lccccc}
\hline \multirow{2}{*}{ Sample } & \multicolumn{3}{c}{ Content (wt\%) } & $\begin{array}{c}\text { BET surface } \\
\text { area }\left(\mathrm{m}^{2} / \mathrm{g}\right)\end{array}$ & $\begin{array}{c}\text { Porous volume } \\
\left(\mathrm{cm}^{3} / \mathrm{g}\right)\end{array}$ \\
\cline { 2 - 4 } & $\mathrm{MoO}_{3}$ & $\mathrm{NiO}$ & $\mathrm{P}_{2} \mathrm{O}_{5}$ & \\
$\mathrm{NiMo}$ & 14.7 & 3.77 & 0.44 & 231 & 0.618 \\
$\mathrm{NiMoP} 1$ & 15.6 & 3.67 & 0.89 & 222 & 0.607 \\
$\mathrm{NiMoP3}$ & 15.1 & 3.70 & 2.00 & 208 & 0.584 \\
$\mathrm{NiMoP} 10$ & 15.5 & 4.70 & 4.70 & 169 & 0.502 \\
$\mathrm{Al}_{2} \mathrm{O}_{3}$ & & & & 265 & 0.789 \\
$\mathrm{P} 1 / \mathrm{Al}_{2} \mathrm{O}_{3}$ & & & & 257 & 0.779 \\
$\mathrm{P} 3 / \mathrm{Al}_{2} \mathrm{O}_{3}$ & & & & 245 & 0.752 \\
$\mathrm{P} 10 / \mathrm{Al}_{2} \mathrm{O}_{3}$ & & & & 210 & 0.648 \\
\hline
\end{tabular}




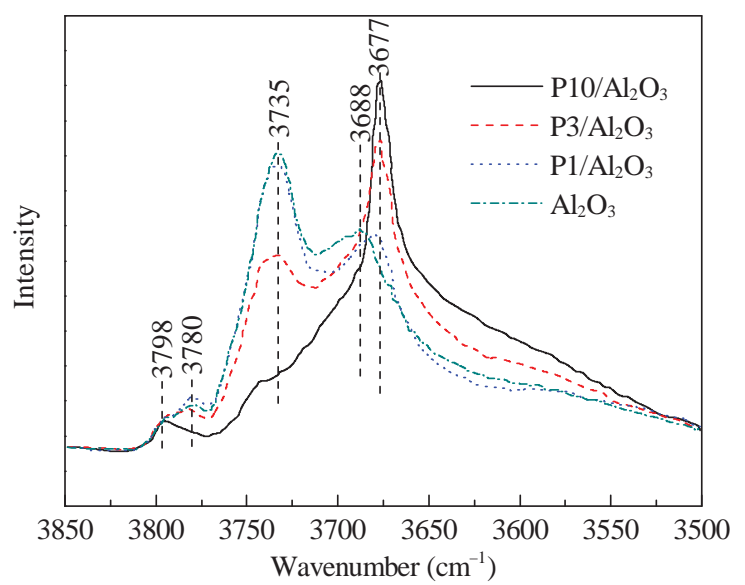

Fig. 1. FT-IR spectra of several $\mathrm{P} / \mathrm{Al}_{2} \mathrm{O}_{3}$ supports.

the four types of Al-OH: Type Ia) and Ib) (Al-OH-Al), Type IIa), and IIb) (Al-OH) which are present on the surface of alumina $[3,15]$. With an increase in phosphorus content, the strength of the $\mathrm{Al}-\mathrm{OH}-\mathrm{Al}$ and $\mathrm{Al}-\mathrm{OH}$ bands on the surface of alumina decreased; and correspondingly, the strength of the $\mathrm{P}-\mathrm{OH}$ band $\left(3677 \mathrm{~cm}^{-1}\right)$ increased. In the case of the $\mathrm{P} 10 / \mathrm{Al}_{2} \mathrm{O}_{3}$ support, almost all the Al-OH-Al bands had disappeared. Part of the $\mathrm{OH}-\mathrm{Al}$ and $\mathrm{Al}-\mathrm{OH}-\mathrm{Al}$ bands were still observed as well as strong $\mathrm{P}-\mathrm{OH}$ bands for the $\mathrm{P} 3 / \mathrm{Al}_{2} \mathrm{O}_{3}$ support. This means that the $\mathrm{P} 3 / \mathrm{Al}_{2} \mathrm{O}_{3}$ support contains more $\mathrm{OH}$ groups on the surface of the support than others, meaning there are more sites to anchor more Mo species and give more acidic sites in the NiMoP3 catalyst.

\subsection{Identification of the porphyrin and its derivatives from $H D N$}

HDN reactions of tetralin solution of $0.10 \mathrm{wt} \%$ porphyrin were carried out on the NiMoP3 catalyst under the conditions of 300 to $360{ }^{\circ} \mathrm{C}$, WHSV $=39 \mathrm{~h}^{-1}$, and $5.0 \mathrm{MPa}$. Figure 2 shows the conversions of porphyrin in HDN obtained by GPC analysis, which was defined as a total conversion and nitrogen removal ratio obtained by GC-FTP and GC-FID analysis, which was defined as HDN conversion. At every reaction temperature, only

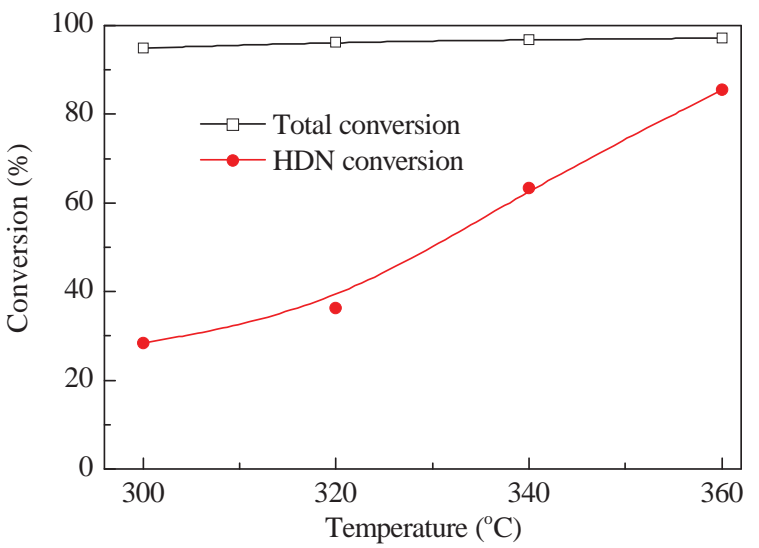

Fig. 2. Total conversion and nitrogen removal ratio by HDN of the porphyrin on the NiMoP3 catalyst at different temperatures.

small amounts of porphyrin and its hydrogenated intermediates were detected by GPC analysis. High total conversions of porphyrin over $95 \%$ even at $300{ }^{\circ} \mathrm{C}$ were observed. In contrast to this, based on the total nitrogen content in the liquid sample after the reaction, the HDN conversion, or nitrogen removal ratios were $29.3 \%, 36.9 \%, 63.8 \%$, and $85.8 \%$ at $300,320,340$, and $360{ }^{\circ} \mathrm{C}$, respectively, as shown in Fig. 2 . This suggests that, the hydrogenolysis of porphyrin occurs easily even at lower temperatures but higher temperatures are required for the hydrodenitrogenation of porphyrin.

After the HDN reaction, nitrogen-containing intermediates and HDN products (i.e. hydrocarbons) in the liquid samples were identified and quantitatively determined by means of GC-FID, GC-MS, and GC-FTD. Figure 3 shows the GC-FID and GC-FTD traces of various liquid samples obtained at each HDN temperature. The hydrocarbons and nitrogen-containing compounds could be detected by GC-FID while only nitrogen-containing compounds could be detected by GC-FTD. Furthermore, the same analytical conditions including the column and temperature program were used for both gas chromatographies. The identification was conducted by comparison of the GC charts shown in Fig. 3.

As an example, Fig. 4 shows a comparison of the GC-FID and
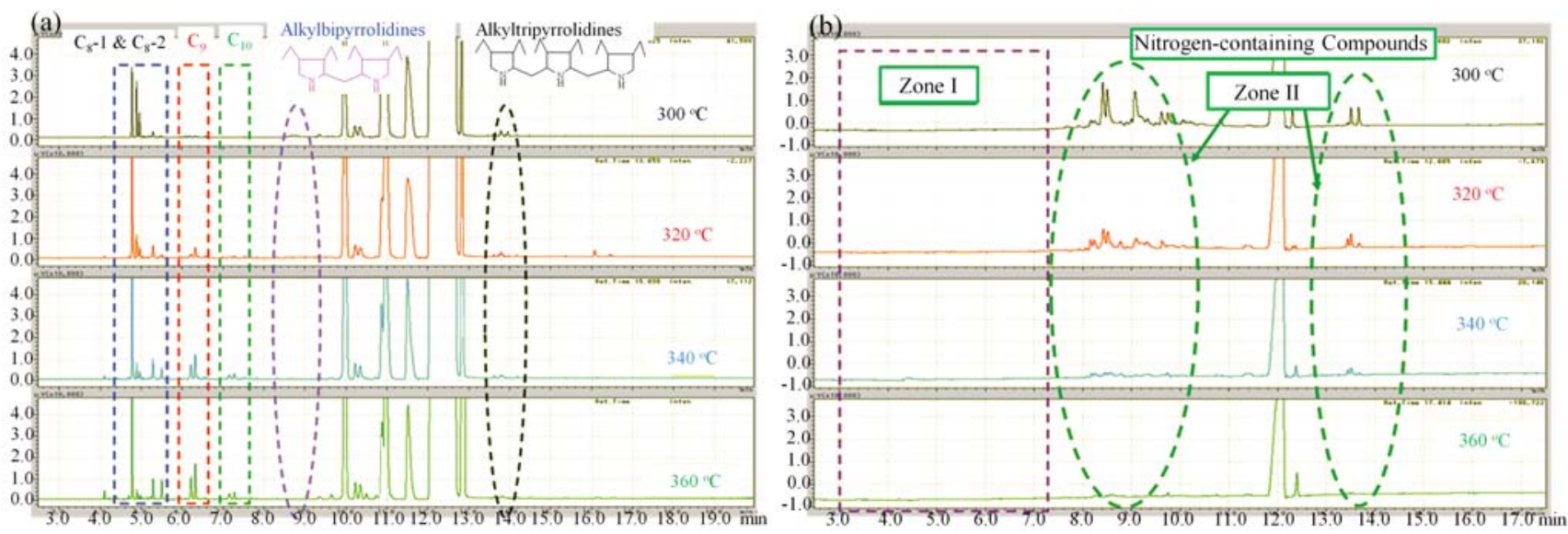

Fig. 3. GC-FID (a) and GC-FTD (b) traces of the liquid product after HDN at different temperatures. 


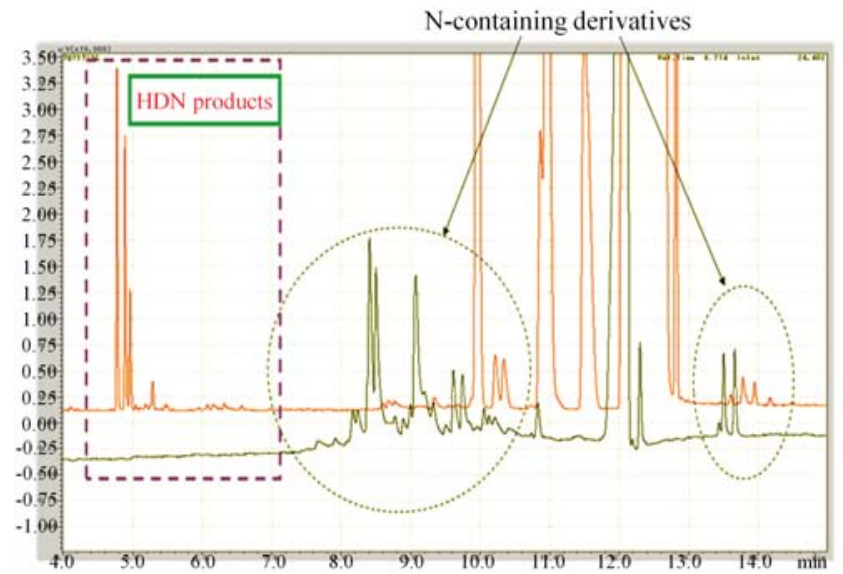

Fig. 4. Comparison of GC-FID and GC-FTD traces of the liquid product after $\mathrm{HDN}$ at $300^{\circ} \mathrm{C}$.

GC-FTD charts of a sample obtained in HDN at $300{ }^{\circ} \mathrm{C}$. The GC charts were divided into two zones in addition to the peaks attributed the tetralin solvent with retention times between 9.5 and $13 \mathrm{~min}$. Zone I with retention times of 4.0 to $8.0 \mathrm{~min}$ corresponding to hydrocarbons produced in HDN, and Zone II with retention times of 8.0 to $10.0 \mathrm{~min}$, and 13.5 to $14.5 \mathrm{~min}$ corresponding to intermediates containing nitrogen derived from the hydrogenolysis of the porphyrin. Similar conclusions were obtained for other samples obtained from HDN at different temperatures as shown in Fig. 3. Moreover, based on the results obtained by GC-MS under the same analytical conditions, individual compounds were identified. The identification results are shown in Fig. 3(a). There were four groups of hydrocarbons: $\mathrm{C}_{8}-1$ ( $\mathrm{C}_{8}$ alkanes), $\mathrm{C}_{8}-2$ ( $\mathrm{C}_{8}$ alkenes), $\mathrm{C}_{9}$ ( $\mathrm{C}_{9}$ alkanes), and $\mathrm{C}_{10}\left(\mathrm{C}_{10}\right.$ alkanes), and two groups of nitrogen-containing compounds: alkyl substituted bipyrrolidines (alkylbipyrrolidines) including bis-(2,3-diethyl-4-methyl tetrahydropyrrolyl)-methane, bis-(2,3-diethyltetrahydropyrrolyl)-methane, and 2,3-dimethyl-4-methyl tetrahydro pyrrolyl-2,3-diethyl-tetrahydro pyrrolyl methane, and alkyl substituted tripyrrolidines (alkyltripyrrolidines).

\subsection{HDN of porphyrin}

To improve the level of analytical precision, the concentrations of the $\mathrm{C}_{8}, \mathrm{C}_{9}$, and $\mathrm{C}_{10}$ hydrocarbons were determined by GC-FID, and those of nitrogen-containing compounds were determined by GC-FTD. Figure 5 shows the changes in the formation rates of products form the HDN of porphyrin with reaction temperature on the NiMoP3 catalyst. At every temperature, no porphyrin and its hydrogenated derivatives were detected. Alternatively, alkylbipyrrolidines, i.e. containing two hydrogenated pyrrole rings, were the main intermediates, and smaller amounts of alkyltripyrrolidines with three hydrogenated pyrrole rings were detected. Although alkyl substituted pyrrole and alkyl substituted pyrrolidine were not detected, the hydrocarbon products derived from the hydrodenitrogenation of these intermediates such as dimethylhexane $\left(\mathrm{C}_{8} \mathrm{H}_{18}\right.$ : $\left.\mathrm{C}_{8}-1\right)$, dimethylhexene $\left(\mathrm{C}_{8} \mathrm{H}_{16}: \mathrm{C}_{8}-2\right)$, ethylmethylhexane $\left(\mathrm{C}_{9}\right.$ hydrocarbon), and diethylhexane ( $\mathrm{C}_{10}$ hydrocarbon) were detected.

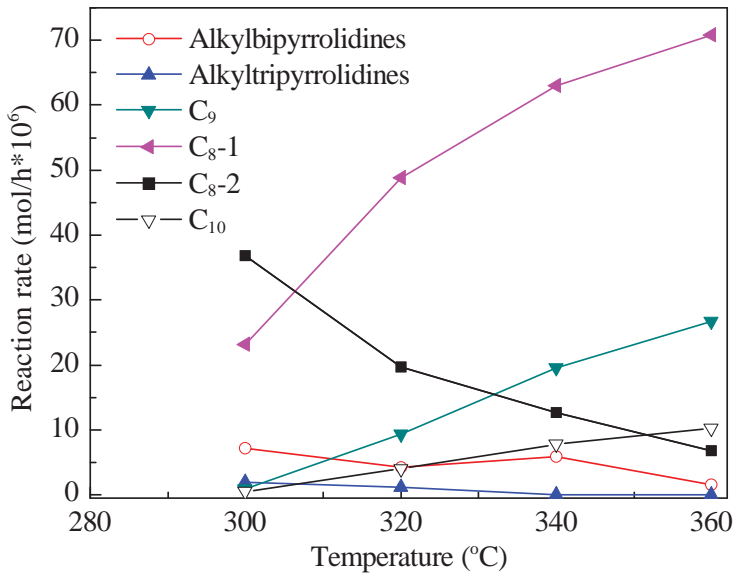

Fig. 5. Reaction rates of products by HDN of the porphyrin on the NiMoP3 catalyst at different temperatures.

The formation rates of the alkylbipyrrolidines and alkyltripyrrolidines decreased with increasing reaction temperature. In contrast to this, the formation rates of the hydrocarbons except for $\mathrm{C}_{8}-2$ increased with increasing reaction temperature.

In order to elucidate the HDN mechanism, the HDN reaction of $0.1 \mathrm{wt} \%$ tetralin solution of porphyrin was carried out under different WHSV. Figures 6 and 7 show the effect of WHSV on the formation rates of the nitrogen-containing compounds and hydrocarbons in various groups produced by the HDN of porphyrin at different temperatures. No hydrocarbons derived from alkylbipyrrolidines and alkyltripyrrolidines via hydrodenitrogenation were detected in any reactions, indicating that these intermediates were formed from the hydrogenolysis of the porphyrin via the cleavage of unsaturated bonds present between the pyrrolidine rings in porphyrin, and directly de-

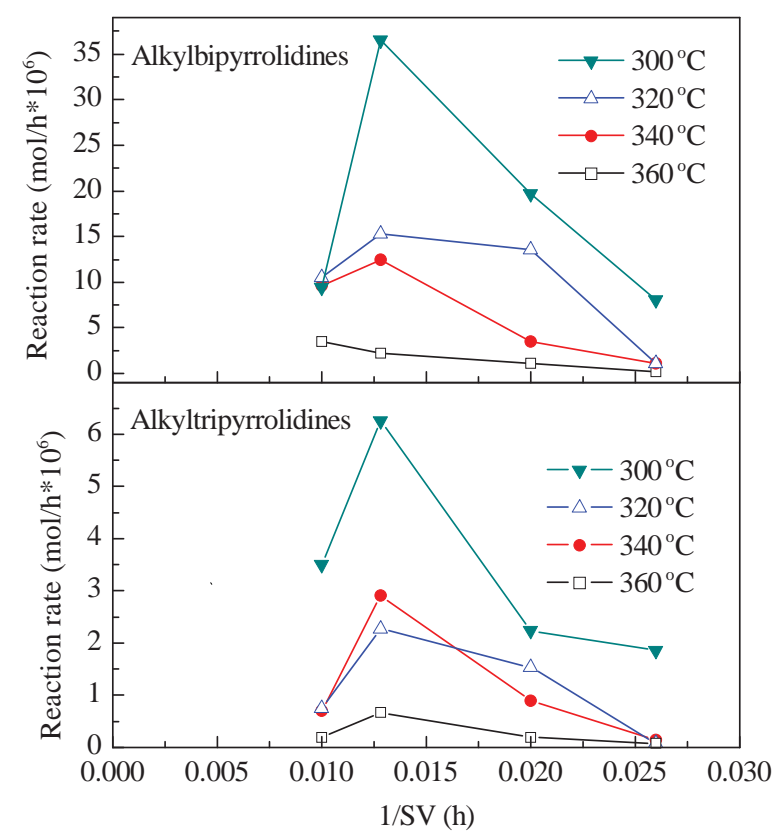

Fig. 6. Effect of WHSV on the formation rates of nitrogen-containing compounds produced by HDN of the porphyrinon the NiMoP3 catalyst at several temperatures. 


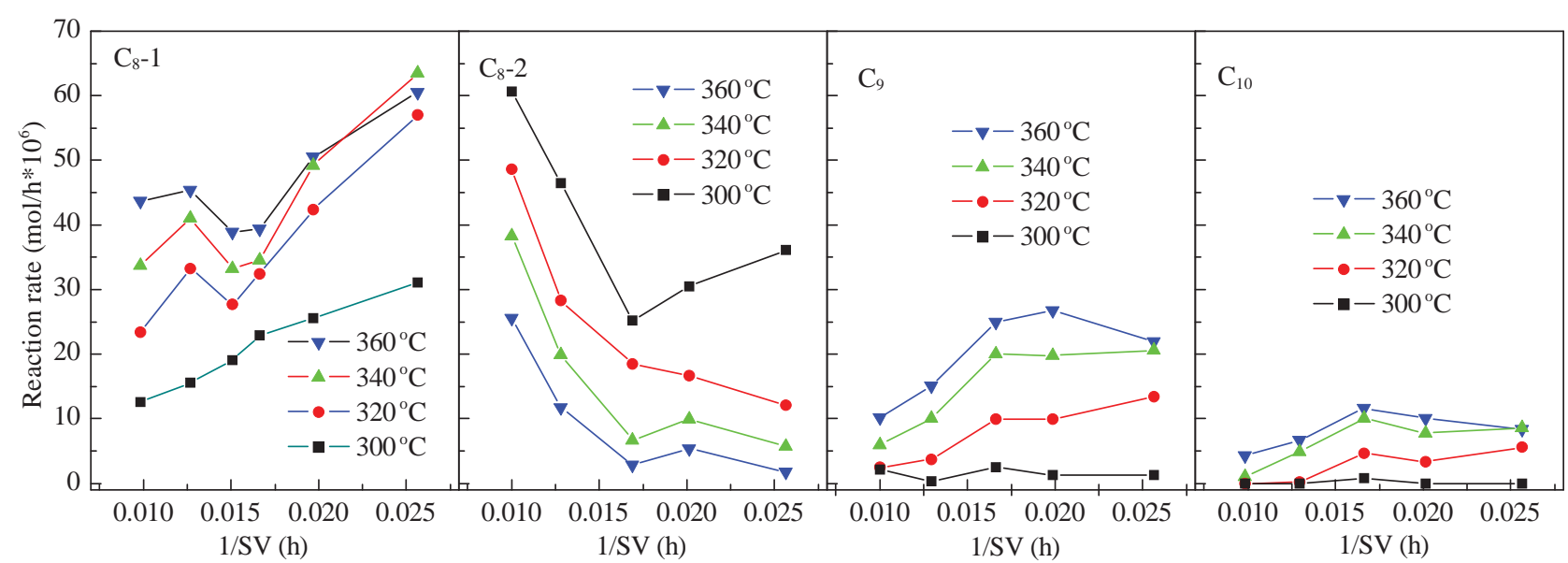

Fig. 7. Effect of WHSV on the formation rates of hydrocarbons produced by HDN of the porphyrinon the NiMoP3 catalyst at several temperatures.

sorbed from the catalyst. This means that their sequential hydrodenitrogenation did not occur under the HDN conditions in the present study.

As shown in Fig. 7, the formation rate of $\mathrm{C}_{8}-1$ increases linearly with increasing $1 / \mathrm{SV}$ while that of $\mathrm{C}_{8}-2$ rapidly decreases at low $1 / \mathrm{SV}$ but slowly decreased at high $1 / \mathrm{SV}$. In contrast, the formation rates of $\mathrm{C}_{9}$ and $\mathrm{C}_{10}$ increased at low $1 / \mathrm{SV}$ but at higher $1 / \mathrm{SV}$ decreased with increasing $1 / \mathrm{SV}$. The tendency became more pronounced at higher temperature. Further, alkylbipyrrolidines and alkyltripyrrolidines showed similar behaviors, i.e., first increased and then decreased with increasing 1/SV, as shown in Fig. 6 . Based on the results, it seems that the conversion of unsaturated hydrocarbons $\mathrm{C}_{8}-2$ into saturated hydrocarbons $\mathrm{C}_{8}-1$ occurs for all $1 / \mathrm{SV}$, while the apparent formation rate of $\mathrm{C}_{8}-2$ increases at higher $1 / \mathrm{SV}$ due to the decrease in the formation rates of the nitrogen-containing precursors, alkyl ( $\mathrm{C}_{5}$ or $\mathrm{C}_{6}$ ) pyrrolidines, which are transformed into $\mathrm{C}_{9}$ or $\mathrm{C}_{10}$ after $\mathrm{HDN}$, resulting in an increase in those of alkyl $\left(\mathrm{C}_{4}\right)$ pyrrolidines, followed by the formation of $\mathrm{C}_{8}-2$. Considering the absence of porphyrin and its hydrogenated intermediates, it is suggested that porphyrin maybe adsorbed onto the catalyst and decomposed by hydrogenolysis into alkyl substituted pyrroles and/or pyrrolidines. Since only bi- and tri-pyrrolidines derived from the hydrogenation of bi- and tri-pyrroles were detected in all the HDN reactions, we suggest that the porphyrin adsorbs onto the catalyst; then the olefin bond between pyrrole rings is hydrogenated and cleaved to give alkyl-substituted bi- and tri-pyrrolidines. Moreover, it is concluded that the HDN rate of the alkyl-substituted pyrrolidine is much faster than the formation rate of alkyl-substituted pyrrolidines because no alkyl-substituted pyrrolidines were detected in any reactions.

Based on the results mentioned above, a HDN reaction pathway of porphyrin is suggested, and is shown in Scheme 1. First, the porphyrin adsorbs onto the catalyst, the olefin bond between pyrrole rings is readily hydrogenated, and simultane-

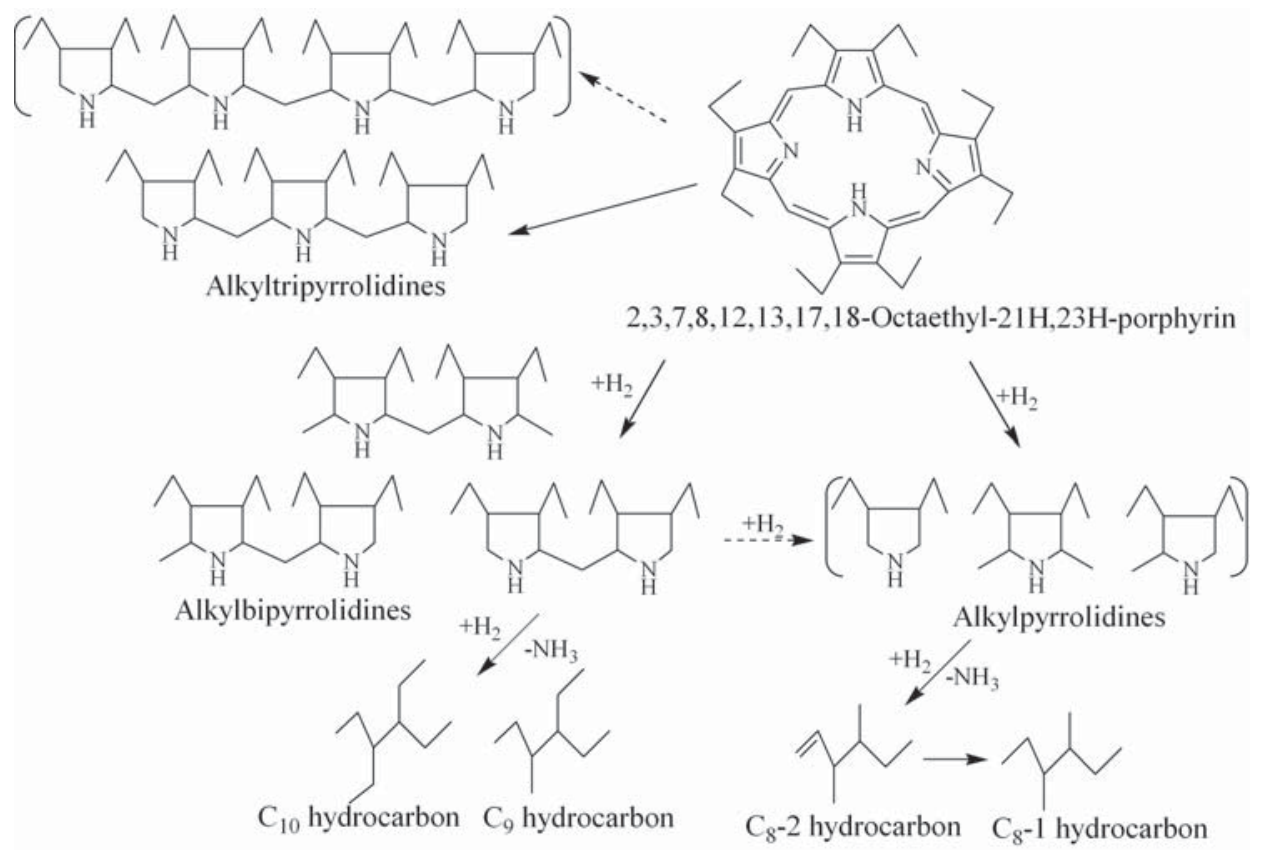

Scheme 1. HDN reaction pathway of the porphyrin. 


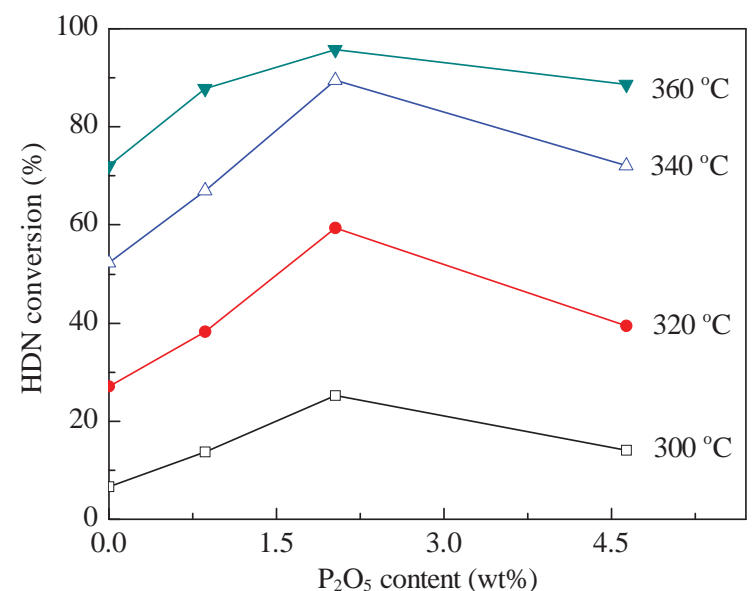

Fig. 8. Effect of phosphorus content on the HDN conversion of the porphyrin on the NiMoP catalysts at different temperatures.

ously cleaved to give alkyl-substituted pyrrolidines, alkylbipyrrolidines and alkyltripyrrolidines. Then, the alkyl-substituted pyrrolidines are further hydrogenated and the $\mathrm{C}-\mathrm{N}$ bonds are cleaved to give $\mathrm{C}_{8}, \mathrm{C}_{9}$, and $\mathrm{C}_{10}$ hydrocarbons. On the other hand, alkylbipyrrolidines and alkyltripyrrolidines can desorb from the catalyst and are not further hydrogenated.

\subsection{Effects of the addition of phosphorus on the NiMo catalysts in the HDN of the porphyrin}

Figure 8 shows the changes in the HDN conversion on $\mathrm{Ni}$ MoP catalysts with different phosphorus contents. At all temperatures, the catalytic activities of the NiMoP catalysts were enhanced by the addition of phosphorus. The NiMoP3 catalyst showed the highest activity.

In order to investigate the addition effect of phosphorus, adsorption experiments using the two probe molecules $\mathrm{NO}$ and $\mathrm{NH}_{3}$ were conducted on the sulfide NiMoP catalysts. The adsorption amounts are listed in Table 2. It is well known that the amount of NO adsorbed indicates the dispersion of Mo, i.e. the size of the cluster of Mo species, because the NO molecule selectively adsorbs on the Mo active site for HDN. The smaller the Mo cluster, the more active sites for hydrogenation there are $[1,16]$. The NiMoP3 catalyst showed the largest adsorption of NO as shown in Table 2. Thus, the Mo species on the catalyst was well dispersed and the catalyst showed the highest activity. However, $\mathrm{NH}_{3}$ adsorbs selectively on the acidic site on the solid catalyst. The adsorption amount of $\mathrm{NH}_{3}$ on the NiMoP catalysts, which represents the number of acidic sites on the catalysts, increased with the addition of phosphorus (Table 2). Thus, the number of acidic site on NiMoP1 and NiMoP3 catalysts was

Table 2

Adsorption amounts of $\mathrm{NO}$ and $\mathrm{NH}_{3}$.

\begin{tabular}{lcc}
\hline \multirow{2}{*}{ Sample } & \multicolumn{2}{c}{ Molar ratio $(\mathrm{mol} / \mathrm{mol})$} \\
\cline { 2 - 3 } & $\mathrm{NO} / \mathrm{Mo}$ & $\mathrm{NH}_{3} / \mathrm{Mo}$ \\
\hline NiMo & 0.135 & 0.29 \\
NiMoP1 & 0.133 & 0.38 \\
NiMoP3 & 0.166 & 0.50 \\
NiMoP10 & 0.110 & 0.42 \\
\hline
\end{tabular}

increased. However, the BET surface area and porous volume of the NiMoP10 catalyst was significantly decreased (Table 1). This indicates that excess phosphorus inhibits the dispersion of Mo and causes the formation of bulk Mo species.

As mentioned above, the amount of NO adsorption represents the number of HDN active sites whereas the amount of $\mathrm{NH}_{3}$ adsorption represents the number of acidic sites on the catalyst, i.e. the number of hydrogenation active sites. The NiMoP3 catalyst shows the largest amount of both $\mathrm{NO}$ and $\mathrm{NH}_{3}$ adsorption. Thus, appropriate amount of phosphorus enhances both the dispersion of active metal and the number of hydrogenation active sites.

\section{Conclusions}

A method of quantitative analysis and identification of a porphyrin and its HDN derivatives was established. In the HDN of the porphyrin, four groups of hydrocarbons: $\mathrm{C}_{8}$ alkanes, $\mathrm{C}_{8}$ alkenes, $\mathrm{C}_{9}$ alkanes, and $\mathrm{C}_{10}$ alkanes, and two groups of nitrogen-containing compounds: alkyl substituted bipyrrolidines (alkylbipyrrolidines), and alkyl substituted tripyrrolidines (alkyltripyrrolidines) were determined. In all HDN reactions, little of the porphyrin and its hydrogenated intermediates were detected after the HDN reaction and over $95 \%$ of total conversion of porphyrin was obtained even temperatures as low as $300^{\circ} \mathrm{C}$. It was found that the hydrogenolysis of the porphyrin occurred at lower temperature easily but higher temperatures are required for the hydrodenitrogenation of the porphyrin and its intermediates. Based on the characterization of the supports and catalysts, it is suggested that the dispersion of Mo is improved and number of weak acidic sites on the NiMoP catalysts increases with the addition of phosphorus.

\section{Acknowledgements}

One author, Qian, would like to acknowledge Dr. Minyuan He's kind invitation to celebrate the 90th birthday of Professor Enze Min.

\section{References}

[1] Kabe T, Ishihara A, Qian W. Hydrodesulfurization and Hydrodenitrogenation: Chemistry and Engineering. New York: Willey, 1999

[2] Prins R. Adv Catal, 2001, 46: 399

[3] Iwamoto R, Grimblot J. Adv Catal, 2000, 44: 417

[4] Qian E W, Abe S, Nojima A, Gunji K, Ishihara A, Ikeda H. Prep ACS, Div Petro Chem, 2006, 51(2): 271

[5] Qian E W, Abe S, Kurahashi T, Kagawa Y, Ikeda H. Prep ACS, Div Petro Chem, 2011, 56(2): 99

[6] Qian W, Shirai H, Ifuku M, Ishihara A, Kabe T. Energy Fuels, 2000, 14: 1205

[7] Kabe T, Qian W, Hirai Y, Li L, Ishihara A.J Catal, 2000, 190: 191

[8] Qian W, Kawano T, Funato A, Ishihara A, Kabe T. Phys Chem Chem Phys, 2001, 3: 261

[9] WangA J, WangY, KabeT, ChenY Y, Ishihara A, QianW. J Catal, 2001, 199: 19

[10] WangD H, Qian W, IshiharaA, KabeT.J Catal, 2001, 203: 322 
[11] Qian W, Yamada S, Ishihara A, Ichinoseki M, KabeT. SekkiyuGakkashi, 2001, 44(4): 225

[12] Qian W, Ishihara A, Aoyama Y, Kabe T. Appl Catal A, 2000, 196: 103
[13] Qian W, Ishihara A, Ogawa S, Kabe T. J Phys Chem, 1994, 98: 907

[14] Kabe T, Qian W, Ogawa S, Ishihara A. J Catal, 1993, 143: 239

[15] Lewis J M, Kydd R A.J Catal, 1991, 132: 465

[16] Daage M, Chianelli R R. J Catal, 1994, 149: 414

\section{Graphical Abstract}

Chin. J. Catal., 2013, 34: 152-158 doi: 10.1016/S1872-2067(11)60514-7

Hydrodenitrogenation of porphyrin on Ni-Mo based catalysts

Eika W. QIAN *, Satoshi ABE, Yusaku KAGAWA, Hiroyuki IKEDA

Tokyo University of Agriculture and Technology, Japan;

Nippon Ketjen Co. Ltd., Japan

The hydrodenitrogenation (HDN) of porphyrins was carried out over the phosphorus containing $\mathrm{NiMo} / \mathrm{Al}_{2} \mathrm{O}_{3}$ catalysts using a fixed-bed flow reaction system. A method of quantitative analysis of the porphyrin and its derivatives produced by HDN was established.

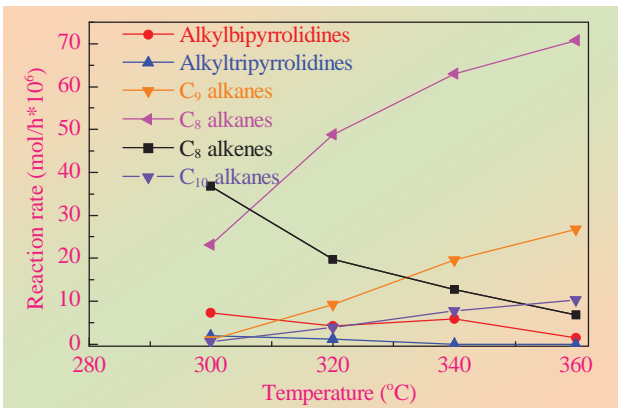

